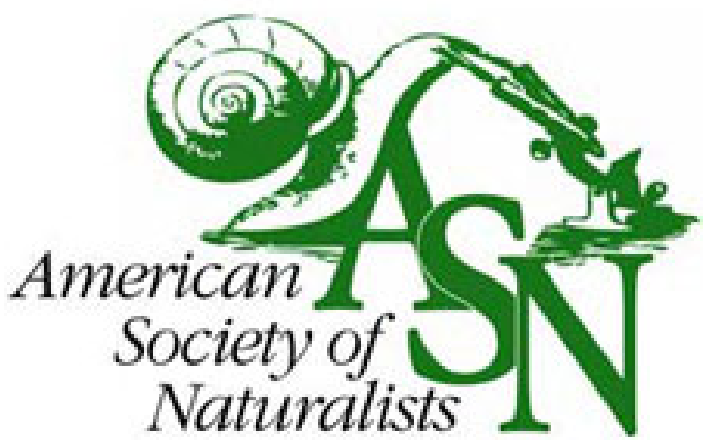

The University of Chicago

Rearing-Group Size Determines Social Competence and Brain Structure in a Cooperatively Breeding Cichlid

Author(s): Stefan Fischer, Mathilde Bessert-Nettelbeck, Alexander Kotrschal and Barbara

Taborsky,

Source: The American Naturalist, (-Not available-), p. 000

Published by: The University of Chicago Press for The American Society of Naturalists

Stable URL: http://www.jstor.org/stable/10.1086/681636

Accessed: 05/05/2015 15:02

Your use of the JSTOR archive indicates your acceptance of the Terms \& Conditions of Use, available at

http://www.jstor.org/page/info/about/policies/terms.jsp

JSTOR is a not-for-profit service that helps scholars, researchers, and students discover, use, and build upon a wide range of content in a trusted digital archive. We use information technology and tools to increase productivity and facilitate new forms of scholarship. For more information about JSTOR, please contact support@jstor.org.

The University of Chicago Press, The American Society of Naturalists, The University of Chicago are collaborating with JSTOR to digitize, preserve and extend access to The American Naturalist. 


\title{
Rearing-Group Size Determines Social Competence and Brain Structure in a Cooperatively Breeding Cichlid
}

\author{
Stefan Fischer, ${ }^{1,2,}$ Mathilde Bessert-Nettelbeck, ${ }^{1}$ Alexander Kotrschal, ${ }^{3}$ and Barbara Taborsky ${ }^{1}$ \\ 1. Division of Behavioural Ecology, Institute of Ecology and Evolution, University of Bern, Wohlenstrasse 50a, 3032 Hinterkappelen, \\ Switzerland; 2. Department of Zoology, University of Cambridge, Cambridge, United Kingdom; 3. Department of Zoology/Ethology, \\ Stockholm University, SE-10691, Stockholm, Sweden \\ Submitted September 29, 2014; Accepted February 20, 2015; Electronically published May 4, 2015 \\ Online enhancements: appendixes. Dryad data: http://dx.doi.org/10.5061/dryad.s0b14.
}

AвsтRACт: Social animals can greatly benefit from well-developed social skills. Because the frequency and diversity of social interactions often increase with the size of social groups, the benefits of advanced social skills can be expected to increase with group size. Variation in social skills often arises during ontogeny, depending on early social experience. Whether variation of social-group sizes affects development of social skills and related changes in brain structures remains unexplored. We investigated whether, in a cooperatively breeding cichlid, early group size (1) shapes social behavior and social skills and (2) induces lasting plastic changes in gross brain structures and (3) whether the development of social skills is confined to a sensitive ontogenetic period. Rearing-group size and the time juveniles spent in these groups interactively influenced the development of social skills and the relative sizes of four main brain regions. We did not detect a sensitive developmental period for the shaping of social behavior within the 2-month experience phase. Instead, our results suggest continuous plastic behavioral changes over time. We discuss how developmental effects on social behavior and brain architecture may adaptively tune phenotypes to their current or future environments.

Keywords: developmental plasticity, early environment, environmental matching, social competence, sensitive periods, brain development.

\section{Introduction}

Social behavior is an important component of an individual's behavioral repertoire that regulates intraspecific interactions, allowing animals to navigate the complexities of their social environment (Oliveira 2009, 2012). For instance, submissive, affiliative, and aggressive behaviors are often employed to establish and stabilize dominance hierarchies within social groups, allowing subordinates to be tolerated by dominants (Taborsky 1982; Kutsukake and

* Corresponding author; e-mail: stefanfischer@gmx.at.

Am. Nat. 2015. Vol. 186, pp. 000-000. (C) 2015 by The University of Chicago. 0003-0147/2015/18601-55780\$15.00. All rights reserved.

DOI: $10.1086 / 681636$
Clutton-Brock 2006; Clutton-Brock et al. 2008; Zöttl et al. 2013). Group members can benefit from an ability to flexibly adjust their social behavior to a given social context and to the social roles, as well as the internal and external states, of interaction partners, an ability referred to as "social competence" (Taborsky and Oliveira 2012). It has been proposed that better social competence is likely to be especially beneficial for individuals living in "complex" social environments (reviewed in Taborsky and Oliveira 2012) and that the complexity of the social environment during early life is crucial in shaping social competence (Branchi et al. 2006; Arnold and Taborsky 2010; Taborsky et al. 2012).

During early development, environmental triggers are often most effective in shaping behavior during so-called sensitive periods. These are defined as periods when the effects of experience on the brain are unusually strong and when certain abilities are readily shaped or modified by experience (Knudsen 2004). In many vertebrates, including humans, the expression of social behavior is influenced by experiences during sensitive periods early in life (Machado and Bachevalier 2003; Bateson and Gluckman 2011; Cunningham et al. 2013; Hollis et al. 2013). However, whether the acquisition of social skills is limited to these sensitive phases is unknown. If the development of adequate behavioral responses were indeed constrained by tight time windows, this might negatively affect future social performance (Scott 1962; Bateson and Gluckman 2011). Alternatively, social skills may stay flexible for a lifetime and are continuously altered in response to gained experiences (West-Eberhard 2003).

If early-life experience can persistently alter the behavior of animals, then corresponding changes in brain morphology and brain gene expression should be expected to occur. For example, differences in the social environment experienced during ontogeny gave rise to short-term (Kotrschal et al. 2012a) or long-term (Gonda et al. 2009, 2013) changes in gross brain structures and persistently affected 
brain gene expression in mammals (Branchi 2009), birds (Banerjee et al. 2012), and fish (e.g., Neolamprologus pulcher; Taborsky et al. 2013).

Most studies that experimentally varied social complexity during ontogeny in order to study plastic responses of social behavior and brain development have compared development in natural or seminatural environments with development in deprived social environments, where important social partners, such as the parents or siblings, were entirely or temporarily removed (see Adkins-Regan and Krakauer 2000; Dettling et al. 2002; Bastian et al. 2003; Levy et al. 2003; Pryce et al. 2005; Macri and Würbel 2006; Arnold and Taborsky 2010; Taborsky et al. 2012). If we are interested in the ecological and evolutionary implications of the plasticity observed in these developmental experiments, it would be desirable to test whether similar reaction norms are expressed when manipulations are done within the natural range of early social environments (see Niemelä and Dingemanse 2014). In highly social species, such as cooperative breeders, many behavioral, physiological, and lifehistory parameters vary with social-group size (Balshine et al. 2001; Russell et al. 2002; Heg et al. 2004; Malueg et al. 2009). Therefore, manipulating the social environment by varying group size within the natural range of this parameter should elicit evolved reaction norms in these species. Larger groups will typically represent an environment more socially complex than smaller groups, because more interactions with more different social partners occur. Thus, we should expect individuals reared in larger groups to develop better social skills than those reared in smaller groups (Taborsky and Oliveira 2012).

We reared young of the cooperatively breeding cichlid $N$. pulcher in large or small family groups to investigate three questions: (1) Does early group size affect the expression of social behavior and the development of social skills? (2) Does variation in early group size induce plastic changes in gross brain structures? and (3) Is there a sensitive developmental period in which early group size produces major behavioral differences? To address the third question, we isolated subgroups of young from their rearing groups at different ontogenetic stages. Neolamprologus pulcher is a suitable model to investigate these questions because (1) it is a cooperatively breeding cichlid (Taborsky 1984) with highly variable group sizes, typically ranging from 3 to 16 group members (Balshine et al. 2001; Heg et al. 2005) and (2) the absence or presence of older family members during early development is known to have lasting effects on social competence (Arnold and Taborsky 2010; Taborsky et al. 2012).

In this study, we reared young $N$. pulcher in natural group sizes and compositions, in which we structured the mixed-sex groups by linear size-based hierarchies (Limberger 1983; Dey et al. 2013). We compared the social be- havior of young kept together with large or small natal groups for different time periods, both during the socialexperience phase and in a standardized social-challenge test after the experience phase. We predicted that fish reared in larger groups would develop better social skills, as shown in other vertebrates exposed to social enrichment (Taborsky and Oliveira 2012), and that the social rearing environment would induce plastic changes in brain morphology (Rosenzweig and Bennett 1996; van Praag et al. 2000; Kotrschal et al. 2012b; Jones et al. 2013). Furthermore, we predicted that, in general, a longer exposure to family groups would favor the acquisition of social skills. If there is a sensitive ontogenetic period for the development of such skills, we expected that the expression of social skills would increase steeply within, but not before or after, the sensitive window.

\section{Methods}

\section{Study Species}

Neolamprologus pulcher is a cooperatively breeding cichlid endemic to the East African Lake Tanganyika (Konings 1998). Most social groups consist of one breeder pair and 1-16 (maximum: 25) helpers participating in territory defense, territory maintenance, and alloparental brood care (Taborsky and Limberger 1981). Helpers vary in relatedness, size, and sex, and they display a size-dependent task specialization (Taborsky and Limberger 1981; Taborsky 1984; Dierkes et al. 2005; Heg et al. 2005; Stiver et al. 2005; Bruintjes and Taborsky 2011). A clutch typically contains 100-200 eggs, which are attached to the walls of the breeding shelter (Taborsky 1982). Nine days after spawning, the larvae have developed into free-swimming fry and are independent of direct brood care.

\section{General Housing Conditions}

The experiment was conducted at the Ethological Station Hasli of the Institute of Ecology and Evolution, University of Bern, under license 16/09 from the Veterinary Service of the Canton Bern, Switzerland. Breeder and helper individuals used to produce and rear broods for this experiment were second- and third-generation offspring of wildcaught fish from the Kasakalawe Point population at the southern tip of Lake Tanganyika, Zambia (for exact geographical coordinates, see Heg et al. 2004). The light: dark cycle was set to $13 \mathrm{~L}: 11 \mathrm{D}$, with $10 \mathrm{~min}$ of dimmed light in the mornings and evenings to simulate light conditions at Lake Tanganyika. Water temperature was $27^{\circ} \pm 1^{\circ} \mathrm{C}$, and biochemical parameters were close to values of southern Lake Tanganyika (B. Taborsky, unpublished data). Standard lengths (from the tip of the snout to the end of the caudal peduncle, i.e., excluding the tail fin) were taken for all breed- 
ers and helpers before the experiment. Family groups of breeders and helpers (see group details on composition below) were kept in 18 200-L tanks equipped with a 2-cm layer of sand and an array of different shelters, namely, nine half flower pots, two small PVC walls, two PVC tubes, and four brown, semitransparent plastic bottles with holes near the water surface. Each tank contained a biological internal filter with continuous aeration. Breeders and helpers were fed daily with commercial food flakes (5 days/week) and frozen zooplankton (1 day/week). To prevent densitydependent food competition, we provided each family group with $3 \%$ of the summed fish biomass present in a given tank. This amount assured an ad lib. food supply for all individuals.

\section{Experimental Design}

We haphazardly selected 18 adult males and 18 adult females from our institute's breeding stock and combined them into 18 breeder pairs. Males were always chosen to be larger than females to mimic natural size differences between breeder-pair members (see Taborsky 1984; Balshine et al. 2001). Nine 200-L tanks were stocked with one breeder pair and one small, immature, unrelated individual to act as a helper for the breeder pair ("small groups"). Another set of nine 200-L tanks was stocked with a breeder pair and 13 adult or immature unrelated fish of different lengths as helpers of the breeder pair ("large groups"; for size compositions, see table A1; tables A1-A3, B1, and C1 available online). Choosing all prospective helpers of the large groups to be of different body sizes is important for obtaining natural group compositions, as natural N. pulcher groups have a linear size-based hierarchy (Dey et al. 2013) in which samesized group members cannot stably coexist. After fish were introduced into the 200-L tanks, we observed daily the ac- ceptance status of all helpers. We scored fish as evicted when they repeatedly received aggression from other group members and were forced to stay close to the water surface, and we removed evicted fish immediately to prevent injuries. All evicted fish survived well after being transferred back to their original home tanks. None of the single helpers in small groups was rejected. Large groups had a mean final stable group size of 9 individuals (range: 6-12).

After the breeder female had produced a clutch (mean clutch size: 86.4 eggs, range: 14-215), we waited for 10 days until fry were swimming freely in the water column and were independent of direct brood care. We defined the day of free swimming as day 0 of our experimental time line (fig. 1). Thus, this marked the beginning of the socialexperience phase. On day 0 and every 10 days during the next 2 months, we removed five siblings from each experimental brood, resulting in six subgroups per brood that had been isolated from their original family for different time periods (see fig. 1). Throughout, we refer to these isolation treatments by the respective experimental day on which siblings were removed from their family groups (i.e., \{isolation day 0 , isolation day $10, \ldots$, isolation day 50$\}$ ). Each of these sibling subgroups was further reared in a separate 10-L tank. From day 0 onward, all experimental broods in the $200-\mathrm{L}$ tanks and all isolation subgroups in the 10 - $\mathrm{L}$ tanks were fed ad lib. twice daily with live Artemia and TetraMin baby food. During the experience phase, mean group size of isolation day 0-50 subgroups was 4.22, and the mean group size of the isolation day 60 subgroup was 18.66 fish. After the end of the experience phase, that is, on experimental day 60 (fig. 1), all juveniles still present in the family-group tanks were also transferred to 10-L tanks in groups of 5 fish or in group sizes as close as possible to 5, keeping juveniles separate by family group of origin. Thus, from day 60 until day 200 (see fig. 1), all juvenile groups were housed in 10-L

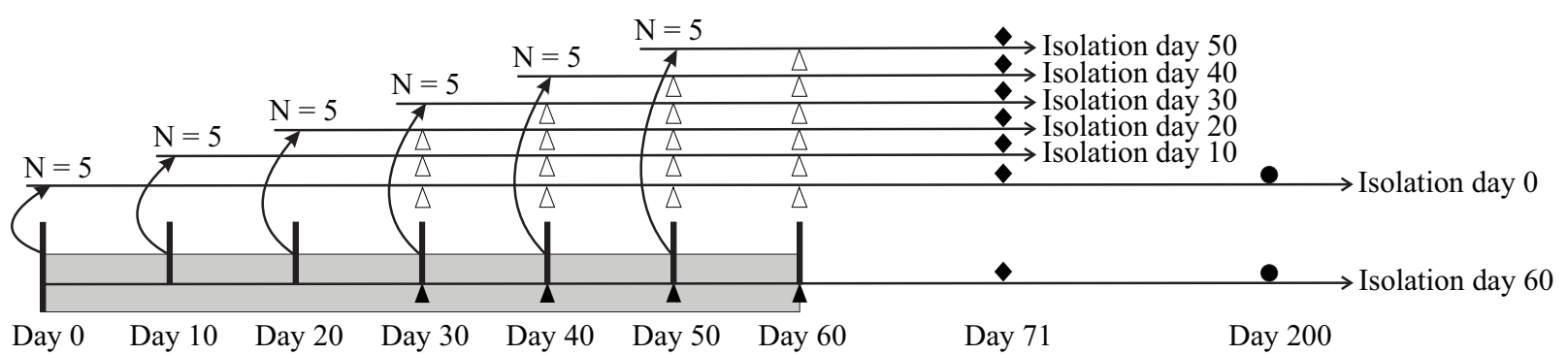

Figure 1: Time line of the experiment illustrated for one family group; this procedure was replicated for 18 family groups ( 9 small and 9 large groups). Curved arrows indicate the transfer of siblings of the experimental broods from their respective family groups to the 10-L isolation tanks. Open triangles indicate the days when juveniles were observed in the 10-L tanks; filled triangles indicate when juveniles were observed and measured in their family-group home tanks; diamonds indicate the social-challenge test on day 71. The shaded area represents the experience phase. Thereafter, all remaining juveniles were transferred to $10-\mathrm{L}$ tanks. The sample size $N$ indicates the number of transferred juveniles per "isolation day." Horizontal arrows indicate the course of the experiment for the different experimental subgroups. Circles indicate the euthanasia of juveniles for the brain morphology analyses. 
tanks under the same conditions. The breeder and helper fish were captured and transferred back to their home tanks in our institute's breeding stock. Thus, isolation day 60 was the end of the experience phase.

\section{Behavioral Recordings}

On experimental days 30,40,50, and 60, we recorded the behavior of the experimentally reared juveniles kept with their family groups (isolation day 60) and of the juveniles in the isolated subgroups (isolation days 0-50; see fig. 1). We observed the young only from day 30 onward, as before that age young $N$. pulcher show nearly no social behavior at all, and they would also be too small to identify any social behavior reliably. All juveniles kept with their family groups (isolation day 60) and groups separated on days $0-20$ (isolation days $0-20$ ) were repeatedly observed at four times on all experimental days. Juveniles isolated on day 30 were observed only on days $40-60$, juveniles isolated on day 40 only on experimental days 50-60, and juveniles isolated on day 50 were observed only on experimental day 60 . We randomly chose the individual to be observed from the shoal of juveniles with help of a random number table (see Arnold and Taborsky 2010 for details). All social behaviors (fin spread, lateral display, head-down display, approach, chase, s-bend, ramming, bow swim, mouth fighting, frontal display, tail quiver, hook display, bumping, and joining; for details of behaviors see Taborsky 1982, 1984; Hamilton et al. 2005; Arnold and Taborsky 2010) of individuals were recorded with the Observer 5 software (Noldus). Before starting a behavioral recording, the observer stayed motionless in front of the tank to let the fish habituate to the observer's presence. Then frequencies of all social behaviors were recorded for 1-5 individuals ( 5 min per individual) in succession. We attempted to obtain data from five randomly chosen individuals from the groups of juveniles that were raised with their family groups until day 60 ; if family groups contained five or fewer individuals, we observed all available juveniles (in total, $n=339$ recordings). Three randomly chosen individuals were observed in each subgroup that had been separated from their original family groups before day 60; if subgroups contained three or fewer individuals, all juveniles were observed (in total, $n=$ 746 recordings). The behavioral recordings were done by S. Fischer and M. Bessert-Nettelbeck.

\section{Size Measurements}

To exclude the possibility that juveniles in large and small groups received different amounts of food, which may influence growth trajectories, we measured the lengths of four randomly chosen experimental juveniles reared together with the family groups at experimental days $40,50,60$, and 71 (if four or fewer individuals were left in a group at a given measuring day, we measured all available juveniles; in total, $n=$ 271 measurements). We chose day 40 to start the measurements because only then are juveniles large and robust enough to be caught and measured without harming them (see Arnold and Taborsky 2010). The standard lengths were measured by placing the fish on a measuring board with a $1.0-\mathrm{mm}$ grid and estimating their lengths to the nearest $0.5 \mathrm{~mm}$ under a binocular microscope.

\section{Social-Challenge Test}

At day 71, we exposed the juveniles from isolation subgroups $\{0,10, \ldots, 60\}$ to a social-challenge test. To test whether improved social skills were acquired during the experience phase, we created a social-challenge test for which we could clearly predict the most adequate behavioral response by the experimental fish. We tested for the ability to switch from being a territory owner to being subordinate toward a larger, dominant conspecific. At first, a test fish was allowed to occupy a territory with its own shelter in the center. Then we added a larger conspecific intruder, which we knew would be strictly dominant toward the smaller test fish because of its physical superiority (Taborsky et al. 2012). In N. pulcher, access to shelters is crucial for survival, and typically each individual occupies its own shelter within a group territory (Balshine et al. 2001). Adding the larger conspecific created a shortage of shelters in the test arena (one shelter for two fish). As intended, the larger conspecific always took over the shelter and became dominant over the smaller test fish. The sole appropriate response of a smaller fish in this situation is to cease territory defense and instead to behave submissively toward the larger conspecific, thereby preventing eviction from the latter's territory and thus the vicinity of the shelter (Taborsky et al. 2012).

The tests were done in seven 20-L tanks equipped with a 2-cm layer of sand, a clay flower pot half serving as shelter, and an air stone for oxygen supply. In the evening of the first day of the test, we haphazardly selected one test fish from each isolation group in which at least one fish had survived until day 71 ( $N=112$ groups) and measured its standard length as described above. Thereafter, the test fish was transferred to one of the 20-L tanks and allowed to acclimatize to the new environment and settle at the shelter, until the next day. A time period of $12 \mathrm{~h}$ is sufficient for an $N$. pulcher juvenile to claim a shelter as the center of its territory and to start defending it against conspecifics (Arnold and Taborsky 2010; Taborsky et al. 2012). On the next day, a 2-mm-larger conspecific was caught from the institute's breeding stock and transferred to the 20-L tank holding the test fish. Directly after the release of the larger 
conspecific, we recorded the frequencies of all submissive and aggressive behaviors of both fish for $10 \mathrm{~min}$. After approximately $6 \mathrm{~h}$, we scored the test fish as being "accepted" or "evicted," depending on the affiliative and submissive behaviors shown toward the larger opponent, the received aggression, the distance between the two fish, and the test fish's use of the shelter. A fish was scored as "accepted" when it showed submissive and affiliative behaviors, stayed close to the larger conspecific, and had access to the shelter. In contrast, an "evicted" individual never showed submissive or affiliative behaviors, received aggression from the larger conspecific, and was forced to stay close to the water surface in one corner of the experimental tank.

\section{Brain Morphology}

At experimental day 200 (fig. 1), we randomly caught and euthanized one fish of each rearing group that was separated from the family group on day 0 and one fish that was isolated on day 60, using an overdose of tricaine methanesulfonate (MS 222), a drug used for anesthesia of fish. We chose day 200 to collect brain samples because at this age the test fish had reached the minimum body size at which we could dissect whole brains without the risk of damaging the tissue. We measured the standard lengths, weighed 23 fish to the closest $0.01 \mathrm{~g}$ with an electronic balance, and stored the heads in a buffered $4 \%$ formaldehyde solution until dissection. We dissected the abdomen of the test fish to determine the sex when possible. Because sex could be determined in only $50 \%$ of the fish, sex was not included in the statistical analysis (see below). This should not pose a problem because $N$. pulcher develop functional gonads, and thus neuroendocrine sex differences, only at a size of around $3.5 \mathrm{~cm}$, which correspond to an age of about 220 days (Taborsky et al. 2007). We collected 24 individual brains, from 12 family groups. Of these 24 brains, 15 were obtained from large groups ( 7 from isolation day 0 , 8 from isolation day 60), and nine brains were collected from small family groups ( 5 from isolation day 0,4 from isolation day 60). The sampling of heads was performed by $M$. Bessert-Nettelbeck, and all brain dissections, digital image analyses, and brain structure measurements were performed by A. Kotrschal, who was blind to the treatment.

To quantify brain structure volumes, digital images of the dorsal, ventral, left, and right sides of the brain were taken through a dissection microscope (Leica MZFLIII) with a digital camera (Leica DFC 490). For each image, the brain was symmetrically positioned so that one hemisphere did not appear larger than the other based on perspective. For paired structures, both sides were measured and the volumes added to give total structure volume. Following Kotrschal et al. (2012b) and using ImageJ, the widths $W$ of six key structures (olfactory bulbs, telenceph- alon, optic tectum, cerebellum, hypothalamus, and dorsal medulla) were determined from dorsal and ventral views, whereas lengths $L$ and heights $H$ were taken from lateral views. The width $W$ was defined as the maximal extension of a given structure perpendicular to the anatomical midline. The length $L$ of a structure was defined as the maximal extension of a structure in parallel to the estimated projection of the brain and the height $H$ as the maximal extension of the structure perpendicular to the estimated projection of the brain. The volume of the brain structures $V$ was determined according to an ellipsoid model (van Staaden et al. 1994). Brain mass was determined to the nearest $0.001 \mathrm{mg}$.

For further analysis, we summed the volumes of the six measured brain structures to obtain a measure of total brain volume. Total brain volume (i.e., the summed volume of the six brain structures) correlated highly with brain mass ( $r=0.983, P<.0001$; Pearson correlation) and can therefore be taken as a reliable estimate of brain mass. Then we calculated the fraction each of the six brain structures made up of the total brain volume as $C_{i}=$ volume $_{\text {brain structure }} /$ total brain volume, where the set of the six fractions $i, C_{i}$, represents the "cerebrotype" of an individual (Clark et al. 2001). Cerebrotypes allow comparison of the relative brain composition independently of total brain size and are frequently used in brain-composition comparisons between species (Clark et al. 2001; Burish et al. 2004; Gonzalez-Voyer and Kolm 2010; Sylvester et al. 2010), but they can also be used to compare brain compositions between individuals.

\section{Statistical Analysis}

For statistical analysis we used R 3.0.2 (R Development Core Team 2013) with the package "Ime4" (Bates et al. 2013). Data were analyzed with linear mixed models (LMMs) and generalized LMMs with a logit link function to account for a binomial error structure, which always included group identity as a random effect. To account for multiple observers of the behavioral recordings during the experience phase and the social-challenge test, we included the observer identity as a random effect in all behavioral analyses.

The frequencies of social behaviors during the experience phase were analyzed in two separate analyses. (1) To test for effects of isolation duration and group size on behavior, fish isolated from their family groups before the end of the experience phase (i.e., isolation days $0,10, \ldots$, 50) were included in one analysis. (2) To test for possible interactive effects of the isolation treatment and the groupsize treatment, we included fish from both rearing-group sizes from the isolation day 0 and isolation day 60 subgroups in one analysis. To account for different observation sample sizes in isolation subgroups with few surviving fish (see above), we took the arithmetic mean over all repeated 
5-min observations of individuals belonging to a given subgroup made on a given observation day.

To disentangle potential effects between the isolation treatment and the group-size treatment for social behaviors of test fish during the social-challenge test, we also performed two separate analyses for the number of submissive and aggressive behaviors per 10-min observation time. First, we analyzed submissive and aggressive behaviors of test fish toward the larger conspecific, using all isolation subgroups. Second, for the sake of comparability with the analyses of the experience phase and brain architecture, we fitted models for both behaviors containing only the isolation day 0 and 60 subgroups. The aggression received by the test fish from the larger conspecific was included as a covariate in the models testing effects on the frequency of submissive and aggressive behaviors, as aggression received from dominant fish is an important trigger of social behavior in $N$. pulcher. In the corresponding figure $2 b, 2 d$, we plotted the residual submission (corrected for received aggression) to take the effect of this covariate on submission into account in the graphs. Table A2 lists the information on the fixed factors, covariates, and interaction terms included in the models and on data transformations, if applied. To simplify the models, we used stepwise backward elimination of nonsignificant interaction terms (Bolker et al. 2009). To validate all models, we inspected
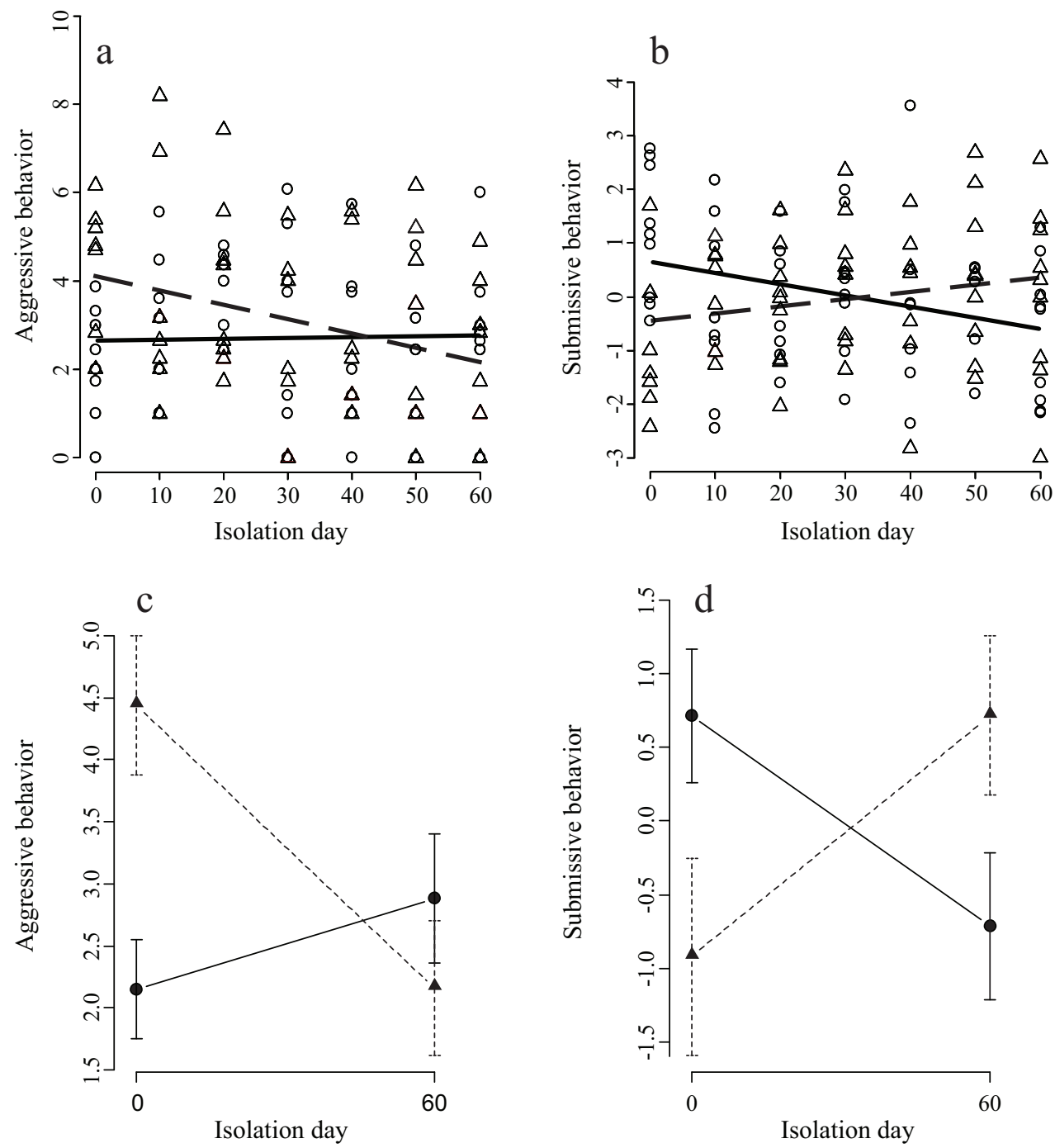

Figure 2: Residual submission (corrected for received aggression) and aggression (both behaviors square root transformed) of test fish during the social-challenge test. $a, b$, Aggression $(a)$ and submission $(b)$ of test fish of all isolated subgroups combined (isolation days 060). $c, d$, Aggression $(c)$ and submission $(d)$ of test fish isolated only on day 0 or day 60 . Triangles and dashed lines represent large groups; circles and solid lines represent small groups. 
the distribution of residuals, predicted versus fitted value plots, and quantile-quantile plots. To obtain $P$ values of model fixed effects, we used likelihood ratio tests (Crawley 2007) and the package "lmerTest" (Kuznetsova et al. 2013).

To analyze the effects of early group size on growth, we calculated specific growth rate (SGR), which gives the percentage of daily growth, between measurement days 40 and 71 as

$$
\mathrm{SGR}=\frac{\ln \left(\mathrm{SL}_{2}\right)-\ln \left(\mathrm{SL}_{1}\right)}{\left(\mathrm{age}_{2}-\mathrm{age}_{1}\right)} \times 100
$$

where $\mathrm{SL}_{1}, \mathrm{SL}_{2}$, age $\mathrm{e}_{1}$, and age $\mathrm{e}_{2}$ are initial and final sizes (standard length) and ages of two successive measurements (Ricker 1975; Wheatherley and Gill 1987).

We did not include body size as a covariate in the behavioral analyses of the social-challenge test because we were missing size records of 11 fish. Excluding these fish from the model would have compromised our statistical power unduly. A separate analysis showed that the rearing conditions did not affect body size at day 71 (the age when the social-challenge test was done; see app. B).

For statistical analysis of brain structure, we performed multidimensional scaling (MDS) on the cerebrotypes, using the module "ALSCAL" of SPSS 20 (IBM, Armonk, NY). The MDS algorithm generates a relational map of brain architectures in a two-dimensional plane, with maximum fidelity to the true distances between cerebrotypes (Clark et al. 2001). MDS allows comparison of brain structures without a priori assumptions about allometric scaling relationships between the different structures (Clark et al. 2001). The matrix of optimally scaled data was calculated on the basis of Euclidean distances. Kruskal's stress formula 1, which gives a normalized value of the residual variance between scaled and raw data, yielded a stress value of 0.138 , which indicates a fair goodness of fit, according to the classification of Kruskal (1964). The proportion of variance of the scaled data accounted for by the raw data was $R^{2}=0.91$. The MDS algorithm calculates the location of cerebrotypes along two dimensions, which can be displayed as twodimensional maps. For our analysis of brain structures, we ran separate LMMs for each of the two dimensions of the map (see table 1) and found that, with respect to our treatments, cerebrotypes clustered only along the first dimension (see "Results").

We also performed separate analyses on the effects of rearing treatment and isolation day on the six measured brain structures. To account for size allometries in the brain architecture, we included total brain mass in these models as a covariate. In figure 3, we corrected the fractions of the different brain parts for brain mass, thereby incorporating the effect of the covariate in the graphs. Data underlying all statistical analyses are deposited in the Dryad
Digital Repository: http://dx.doi.org/10.5061/dryad.s0b14 (Fischer et al. 2015).

\section{Results}

\section{Experience Phase}

Analyzing the subgroups of juveniles separated between isolation days 0 and 50, we found that individuals that were isolated later from their respective family groups showed less aggression and less submission (see the factor "isolation day" in table $2 a, 2 b$ ). Furthermore, older test fish showed more social behavior, which is reflected by higher frequencies of submissive and aggressive behavior with increasing age (see the factor "observation day" in table $2 a, 2 b$ ). Strikingly, there was a significant interaction between treatment and day of isolation for both aggression and submission (fig. $4 a, 4 b$; table $2 a, 2 b$ ). Fish originating from small groups decreased their aggression the longer they had stayed together with their family groups, whereas in fish originating from large groups, the aggression rate was relatively unaffected by isolation day (fig. $4 a$; table $2 a$ ). Contrary to aggressive behavior, fish from large families showed more submission the longer they had been together with their family group, whereas fish originating from small groups expressed submission at a constant rate (fig. $4 b$; table $3 b$ ). These results were not affected by the fact that as a result of the experimental design, two of the isolation subgroups (isolation days 0 and 10) had a longer lag time between isolation day and the observation days (see app. C).

In the comparisons of isolation day 0 and 60 subgroups reared in large and small groups, aggressive behavior was influenced only by isolation day and again by the age of the fish. Regardless of group size of origin, fish isolated on day 0 showed more aggression than isolation-day-60 fish (fig. $4 c$; see the factor "isolation day" in table $2 c$ ). Older fish showed significantly more aggression (see the factor "observation day" in table $2 c$ ). In contrast, the amount of submission shown by individuals isolated on days 0 and 60 was interactively influenced by group size of origin (fig. $4 d$; see the interaction term "treatment $\times$ isolation day" in table $2 d$ ). Among fish already isolated on day 0 , individuals reared in large groups showed less submission than fish reared in small groups, whereas the opposite pattern was found in fish isolated only on day 60 (fig. $4 d$; table $2 d$ ). Also, this analysis revealed that older fish showed more submissive behavior (factor "observation day" in table $2 d$ ).

\section{Growth Rate}

There was no difference in specific growth rates between fish reared in large groups and those raised in small groups (table A3). Overall, there was a very weak tendency ( $P=$ .095) for growth to accelerate with age (table A3). 
Table 1: Comparisons of body size and brain architecture of test fish on day 200

\begin{tabular}{|c|c|c|c|}
\hline Factor & Estimate \pm SE & $t$ & $P$ \\
\hline \multicolumn{4}{|l|}{$a$, Body length: } \\
\hline Intercept & $2.448 \pm .024$ & 103.426 & $<.001$ \\
\hline Treatment & $.02 \pm .028$ & .726 & .481 \\
\hline Isolation day & $-.08 \pm .023$ & -3.523 & .004 \\
\hline \multicolumn{4}{|l|}{$b$, Total brain mass: } \\
\hline Intercept & $1.237 \pm .011$ & 108.707 & $<.001$ \\
\hline Treatment & $-.01 \pm .013$ & -.764 & .462 \\
\hline Isolation day & $-.019 \pm .011$ & -1.736 & .102 \\
\hline Body weight & $.463 \pm .031$ & 14.893 & $<.001$ \\
\hline \multicolumn{4}{|l|}{$c$, MDS scores } \\
\hline \multicolumn{4}{|l|}{ Dimension 1: } \\
\hline Intercept & $-3.529 \pm 3.306$ & -1.067 & .300 \\
\hline Treatment & $-1.375 \pm .622$ & -2.209 & .049 \\
\hline Isolation day & $-.034 \pm .011$ & -3.053 & .009 \\
\hline Brain weight & $4.192 \pm 2.885$ & 1.453 & .163 \\
\hline Treatment $\times$ isolation day & $.041 \pm .01$ & 3.011 & .022 \\
\hline \multicolumn{4}{|l|}{ Dimension 2: } \\
\hline Intercept & $-2.933 \pm 2.296$ & -1.277 & .261 \\
\hline Treatment & $-.340 \pm .308$ & -1.103 & .283 \\
\hline Isolation day & $.008 \pm .006$ & 1.263 & .221 \\
\hline Brain weight & $2.641 \pm 1.974$ & 1.338 & .196 \\
\hline \multicolumn{4}{|l|}{$d$, Brain volume fractions: } \\
\hline \multicolumn{4}{|l|}{ Optic tectum: } \\
\hline Intercept & $.489 \pm .046$ & 10.699 & $<.001$ \\
\hline Treatment & $.017 \pm .009$ & 2.005 & .060 \\
\hline Isolation day & $.028 \pm .009$ & 3.082 & .009 \\
\hline Brain weight & $-.045 \pm .040$ & -1.132 & .273 \\
\hline Treatment $\times$ isolation day & $-.032 \pm .011$ & -2.859 & .007 \\
\hline \multicolumn{4}{|l|}{ Hypothalamus: } \\
\hline Intercept & $.140 \pm .033$ & 4.301 & $<.001$ \\
\hline Treatment & $-.013 \pm .006$ & -2.156 & .044 \\
\hline Isolation day & $-.012 \pm .007$ & -1.642 & .117 \\
\hline Brain weight & $.004 \pm .029$ & .137 & .892 \\
\hline Treatment $\times$ isolation day & $.019 \pm .009$ & 2.175 & .021 \\
\hline \multicolumn{4}{|l|}{ Telencephalon: } \\
\hline Intercept & $.249 \pm .037$ & 6.629 & $<.001$ \\
\hline Treatment & $.005 \pm .005$ & 1.064 & .300 \\
\hline Isolation day & $-.010 \pm .006$ & -1.690 & .107 \\
\hline Brain weight & $-.032 \pm .031$ & -1.012 & .324 \\
\hline \multicolumn{4}{|l|}{ Cerebellum: } \\
\hline Intercept & $.025 \pm .022$ & 1.133 & .279 \\
\hline Treatment & $-.011 \pm .005$ & -2.332 & .034 \\
\hline Isolation day & $-.007 \pm .00$ & -1.670 & .130 \\
\hline Brain weight & $.100 \pm .019$ & 5.177 & $<.001$ \\
\hline Isolation day $\times$ treatment & $.017 \pm .005$ & 3.415 & .006 \\
\hline \multicolumn{4}{|l|}{ Dorsal medulla: } \\
\hline Intercept & $.083 \pm .023$ & 3.639 & .002 \\
\hline Treatment & $.005 \pm .004$ & 1.066 & .300 \\
\hline Isolation day & $.003 \pm .005$ & .716 & .485 \\
\hline Brain weight & $-.023 \pm .020$ & -1.158 & .262 \\
\hline Treatment $\times$ isolation day & $-.010 \pm .006$ & -1.671 & .082 \\
\hline \multicolumn{4}{|l|}{ Olfactory bulbs: } \\
\hline Intercept & $.009 \pm .007$ & 1.382 & .183 \\
\hline Treatment & $.000 \pm .000$ & .235 & .817 \\
\hline Isolation day & $.000 \pm .001$ & -.163 & .872 \\
\hline Brain volume & $-.002 \pm .006$ & -.377 & .710 \\
\hline
\end{tabular}

Note: Comparisons of test fish separated either on day 0 or on day 60 from their respective family groups. MDS scores: multidimensional scaling scores for the two dimensions of the scaled cerebrotypes. Brain volume fractions: relative sizes of the separate volume fractions of brain structures. Treatment: rearing of juveniles in small or large groups. Isolation day: experimental day when juveniles were isolated from their family group. Observation day: age of the test fish when observed. The reference category for the treatment estimate is small groups; that for the isolation day estimate is isolation day $0 . N=14$ family groups and 24 (23 in $b$ ) test fish. Boldface indicates $P<.05$; italics indicate $.05<P<.1$. 

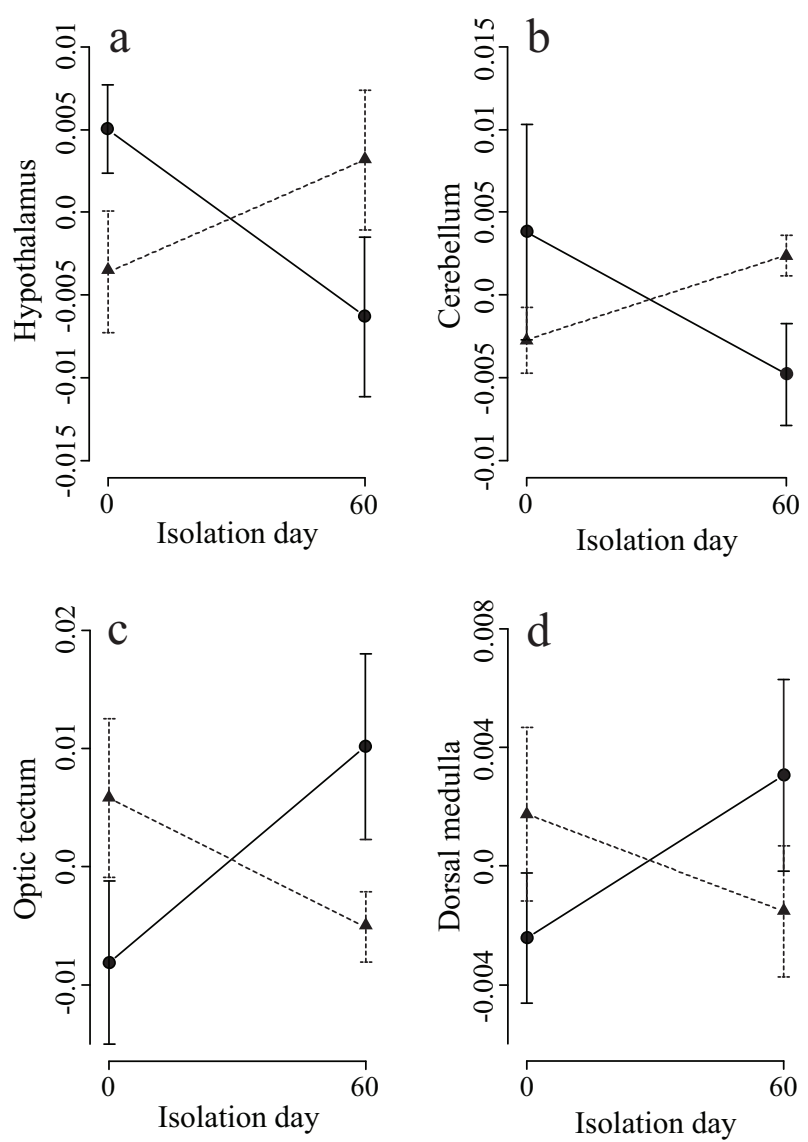

Figure 3: Volume fractions (residuals; corrected for brain mass) of the hypothalamus $(a)$, cerebellum $(b)$, optic tectum $(c)$, and dorsal medulla $(d)$ of fish reared in small (circles) or large (triangles) groups separated at day 0 or day 60 from their respective family groups.

\section{Social-Challenge Test}

When confronted with a larger conspecific in the socialchallenge test at day 71, individuals generally increased their submissive and aggressive behaviors with increasing aggression received from the conspecific (see the significant covariate "received aggression" in table $3 a, 3 c$ ). Fish from large groups showed less aggression toward the larger conspecific the longer they had been reared with their family groups, whereas fish from small groups displayed aggression independently of the day of isolation (fig. $2 a$; see the significant interaction term "treatment $\times$ isolation day" in table $3 a$ ). A separate analysis including only the isolation day 0 and 60 subgroups revealed a similar significant interaction among early group size and day of isolation (fig. $2 c$; table $3 b$ ). Fish reared in large groups showed less aggressive behavior if isolated on day 60 than fish reared in small groups (fig. $2 c$ ). Fish isolated on day 0 showed the opposite pattern (fig. 2c).
Opposite to the results for aggression, fish from large groups displayed more submission per received aggression if during the experience phase they had been reared within the family group for a longer time period. Fish from small family groups showed the opposite pattern (fig. $2 b$; see the significant interaction term "treatment $x$ isolation day $\times$ rec. aggr." in table $3 c$ ). Also, the separate analysis for fish isolated on day 0 or day 60 revealed a significant three-way interaction between rearing-group size, day of isolation, and received aggression from the larger conspecific (table $3 d$; fig. $2 d$ ). Fish that had stayed in the family group until the end of the experience phase (isolation day 60 subgroup) showed more submission per received aggression when originating from large groups (fig. $2 d$; table $3 d$ ); fish isolated on day 0 showed the opposite pattern (fig. $2 d$ ).

The likelihood that a test fish was accepted by the larger conspecific, as determined $6 \mathrm{~h}$ after first contact, tended to be greater if the latter had shown less aggression during the first $10 \mathrm{~min}$ of contact (see the factor "received aggression" in table $3 e$ ). Interestingly, rearing-group size and received aggression from the larger conspecific tended to influence acceptance interactively. Fish from large groups were more likely to be accepted when rates of aggression by the larger conspecific were high, whereas the opposite tendency held for fish reared in small groups (see positive estimate for the interaction term "treatment $\times$ rec. aggr." in table $3 e$ ).

\section{Brain Size and Morphology}

Body size of the fish euthanized for brain sampling at an age of 200 days did not differ between rearing treatments, but fish separated on day 60 were smaller than fish separated at day 0 (see the factor "isolation day" in table $1 a$ ). Total brain mass relative to fish body mass (included as covariate) was not affected by rearing-group size or isolation day (table $1 b$ ).

The MDS scores of dimension 1, and thus the location of cerebrotypes along this dimension, were affected by day of isolation (day 0 or day 60) as well as by treatment (small or large rearing-group size), and there was a significant interactive effect of rearing treatment and day of isolation on cerebrotype location (table $1 c$ ). In contrast, cerebrotype location along the second MDS dimension was not affected by rearing history or day of isolation (table $1 c$ ).

Separate analyses of the six measured brain structures suggest that rearing-group size affected four brain structures interactively with the isolation day (fig. 3; table 1d). Fish reared in large groups had a relatively larger hypothalamus and cerebellum if separated on day 60, compared to fish reared in small groups, whereas the opposite pattern was found for fish isolated on day 0 (fig. $3 a, 3 b$; table $1 d$ ). In contrast, fish reared in large groups had a relatively smaller 
Table 2: Behavior of test fish during the experience phase

\begin{tabular}{|c|c|c|c|}
\hline Factor & Estimate $\pm \mathrm{SE}$ & $t$ & $P$ \\
\hline \multicolumn{4}{|l|}{ Isolation days $0-50$ : } \\
\hline \multicolumn{4}{|l|}{$a$, Aggressive behavior: } \\
\hline Intercept & $.842 \pm .332$ & 2.540 & .004 \\
\hline Treatment & $-.094 \pm .156$ & -.602 & .180 \\
\hline Isolation day & $-.012 \pm .003$ & -3.791 & $<.001$ \\
\hline Observation day & $.007 \pm .003$ & 1.997 & .047 \\
\hline Treatment $\times$ isolation day & $.016 \pm .005$ & 3.530 & $<.001$ \\
\hline \multicolumn{4}{|l|}{$b$, Submissive behavior: } \\
\hline Intercept & $-.528 \pm .178$ & -2.972 & .004 \\
\hline Treatment & $-.058 \pm .171$ & -.340 & .736 \\
\hline Isolation day & $-.006 \pm .003$ & -1.938 & .049 \\
\hline Observation day & $.023 \pm .003$ & 6.876 & $<.001$ \\
\hline Treatment $\times$ isolation day & $.012 \pm .005$ & 2.659 & .008 \\
\hline \multicolumn{4}{|l|}{ Isolation day 0 or 60 : } \\
\hline \multicolumn{4}{|l|}{$c$, Aggressive behavior: } \\
\hline Intercept & $.563 \pm .239$ & 2.353 & .037 \\
\hline Treatment & $.201 \pm .136$ & 1.476 & .131 \\
\hline Isolation day & $-.255 \pm .084$ & -3.052 & .002 \\
\hline Observation day & $.010 \pm .004$ & 2.678 & .007 \\
\hline \multicolumn{4}{|l|}{$d$, Submissive behavior: } \\
\hline Intercept & $-.121 \pm .238$ & -.507 & .613 \\
\hline Treatment & $-.221 \pm .224$ & -.985 & .332 \\
\hline Isolation day & $-.195 \pm .127$ & -1.538 & .127 \\
\hline Observation day & $.018 \pm .004$ & 4.091 & $<.001$ \\
\hline Isolation day $\times$ treatment & $.447 \pm .209$ & 2.140 & .032 \\
\hline
\end{tabular}

Note: Aggressive $(a, c)$ and submissive $(b, d)$ behavior was recorded at observation days $30,40,50$, and 60 . For factor names, see table 1 . The reference category for the treatment estimate is small groups; that for the isolation-day estimate in $c$ and $d$ is isolation day 0 ; in $a$ and $b$, isolation day was included as a covariate. $N=18$ family groups and 756 observations for test fish isolated between day 0 and day 50; 505 observations for test fish separated on days 0 and 60 . Boldface indicates $P<.05$.

optic tectum and tended to have a smaller dorsal medulla if isolated on day 60, compared to fish reared in small groups. Again, the opposite pattern was found for fish isolated on day 0 (fig. $3 c, 3 d$; table $1 d$ ). The volume fractions of the telencephalon and the olfactory bulbs did not depend on rearing-group size or isolation day (table $1 d$ ).

\section{Discussion}

Here we investigated experimentally how the size of social groups and the duration spent in social groups during early ontogeny affect the development of social behavior and brain morphology in a cooperatively breeding cichlid. In brief, Neolamprologus pulcher reared in large groups expressed more social behaviors during the experience phase. When establishing social hierarchies after the experience phase, fish reared in large groups showed more submissive and less aggressive behavior toward a larger conspecific. This behavioral response increases the chances of being tolerated in the territory of a larger, socially dominant conspecific, which greatly enhances the survival chances of smaller, subordinate individuals under natural conditions. Rearing- group size and the time juveniles spent within rearing groups interactively influenced the behavior during hierarchy formation. Furthermore, rearing-group size and time in the groups interactively affected brain architecture, as measured 5 months after the end of the rearing treatments. Surprisingly, we found no clear indication of a sensitive period in the development of social behaviors.

The ultimate likelihood of being tolerated by dominant conspecifics tended to be interactively influenced by rearinggroup size and the received aggression from the dominant fish at first contact. This suggests that juveniles reared in large groups might benefit from better ability to cope with social challenges. Acceptance even under high rates of aggression by the dominant might have been achieved because these fish displayed more submission per received aggression than did fish reared in small groups. High ratios of submission per received aggression are known to appease dominants and to increase the likelihood of being accepted in a social group (Taborsky 1985; Bergmüller and Taborsky 2005; Fischer et al. 2014b).

Although several previous studies reported conclusive evidence that the early social environment can persistently 

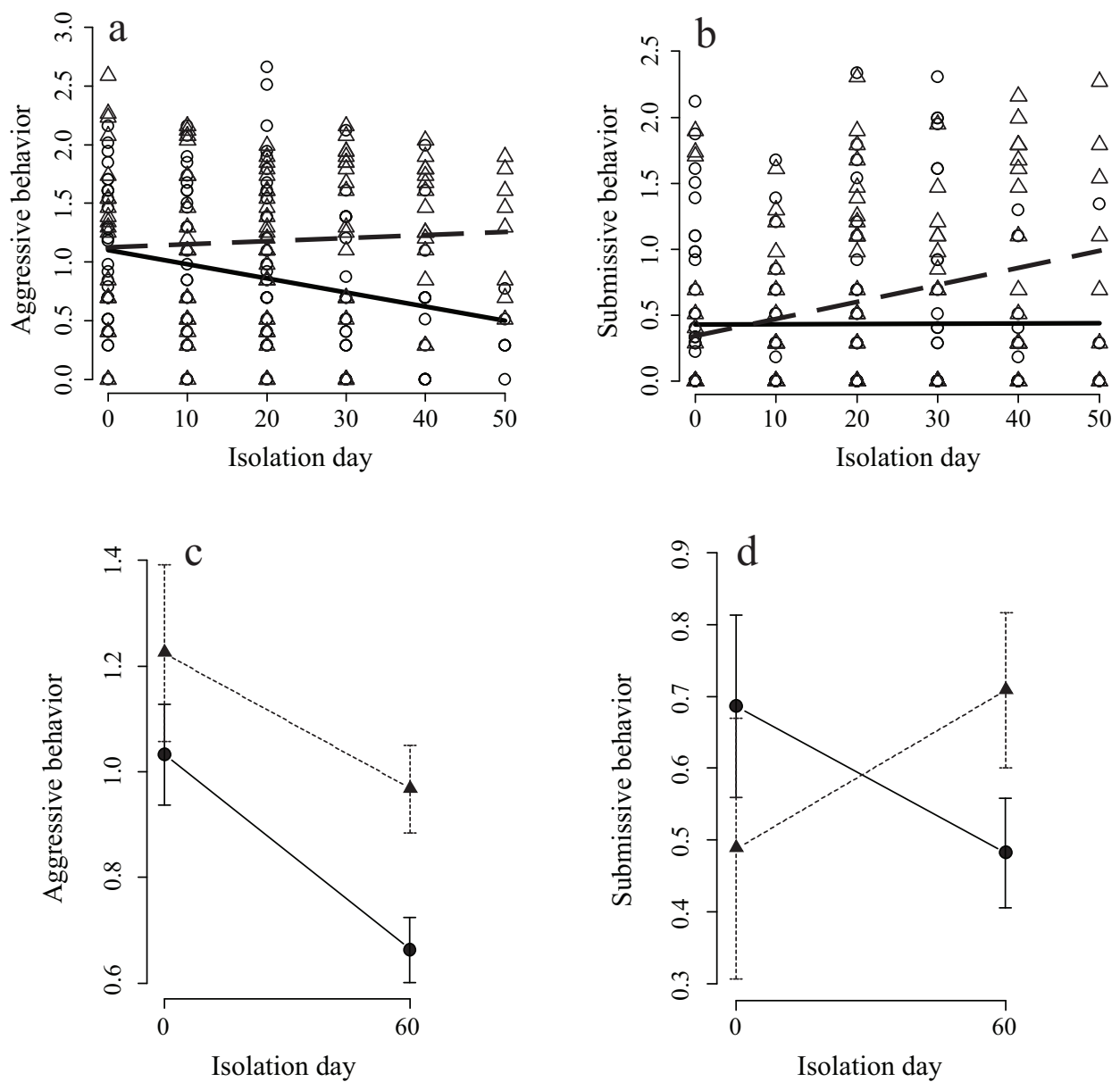

Figure 4: Behavior of juveniles during the experience phase. $a, b$, Number of aggressive $(a)$ and submissive $(b)$ behaviors (both log transformed) of test fish separated from their group starting from isolation day 0 until isolation day 50; recordings were done in separate 10-L tanks with groups of $2-4$ individuals. $c$, $d$, Number of aggressive behaviors ( $c$; log transformed) and submissive behaviors ( $d$; square root transformed) of test fish separated on isolation days 0 and 60 from their groups. Triangles and dashed lines represent large groups; circles and solid lines represent small groups.

influence the social behavior of vertebrates later in life (mammals: Bester-Meredith and Marler 2007; Gracceva et al. 2011; birds: Bertin et al. 2007; White et al. 2010; fish: Moretz et al. 2007; Chapman et al. 2008), the behavioral mechanisms causing such effects are poorly understood in most of these systems, as the test animals are often not observed during the experience phase. Studies in laboratory rodents suggest that the frequency and quality of maternal care shape later social behavior via a reprogramming of the stress response (Branchi et al. 2006; Champagne and Meaney 2007). However, in N. pulcher, direct social interactions between older group members and small juveniles are virtually absent (Arnold and Taborsky 2010; this study; S. Fischer, personal observation), because (allo-)parental care after young reach the free-swimming stage is restricted to guarding. The lack of interactions with older fish makes social learning from older group members highly unlikely. Furthermore, differ- ences in food availability cannot explain the long-term effects, as growth rates did not differ between juveniles reared within small and those reared within large family groups. This suggests that there are indirect effects of group size on social behavior, such as the perception of environmental risk. In the wild, large social groups of $N$. pulcher represent a lowrisk environment with enhanced juvenile survival (Brouwer et al. 2005). Being part of a larger, safer natal group may enhance the motivation of juveniles to engage in more social interactions with siblings (see Arnold and Taborsky 2010; this study), which in turn is likely to enhance the opportunities to acquire social skills.

In the past decades, many studies have demonstrated the ability of genotypes to alter the phenotype in response to environmental cues perceived early in life, and the importance of this often irreversible "developmental plasticity" for organismal evolution has been recognized (West-Eberhard 
Table 3: Behavior and acceptance of test fish in the social-challenge test

\begin{tabular}{|c|c|c|c|}
\hline Factor & Estimate $\pm \mathrm{SE}$ & $t / z$ & $P$ \\
\hline \multicolumn{4}{|l|}{ a, Aggression: } \\
\hline Intercept & $.799 \pm .514$ & 1.555 & .129 \\
\hline Treatment & $1.287 \pm .556$ & 2.316 & .022 \\
\hline Isolation day & $.011 \pm .011$ & 1.019 & .311 \\
\hline Received aggression & $.486 \pm .092$ & 5.301 & $<.001$ \\
\hline Treatment $\times$ isolation day & $-.034 \pm .015$ & -2.207 & .029 \\
\hline \multicolumn{4}{|l|}{$b$, Aggression (isolation day 0 and 60 ): } \\
\hline Intercept & $.151 \pm .647$ & .234 & .817 \\
\hline Treatment & $2.255 \pm .607$ & 3.713 & $<.001$ \\
\hline Isolation day & $1.420 \pm .595$ & 2.389 & .024 \\
\hline Received aggression & $.497 \pm .126$ & 3.937 & $<.001$ \\
\hline Treatment $\times$ isolation day & $-3.121 \pm .832$ & -3.751 & $<.001$ \\
\hline \multicolumn{4}{|l|}{$c$, Submission: } \\
\hline Intercept & $.428 \pm .909$ & .471 & .638 \\
\hline Treatment & $-.388 \pm 1.235$ & -.286 & .754 \\
\hline Isolation day & $.020 \pm .022$ & .911 & .364 \\
\hline Received aggression & $.668 \pm .222$ & 3.006 & .003 \\
\hline Treatment $\times$ isolation day & $-.029 \pm .030$ & -.955 & .342 \\
\hline Isolation day $\times$ received aggression & $-.013 \pm .006$ & -2.272 & .025 \\
\hline Treatment $\times$ received aggression & $-.271 \pm .292$ & -.927 & .356 \\
\hline Treatment $\times$ isolation day $\times$ received aggression & $.021 \pm .008$ & 2.624 & .010 \\
\hline \multicolumn{4}{|l|}{$d$, Submission (isolation days 0 and 60 ): } \\
\hline Intercept & $.941 \pm 1.470$ & .640 & .529 \\
\hline Treatment & $-.904 \pm 1.949$ & -.464 & .647 \\
\hline Isolation day & $-.090 \pm 1.640$ & -.055 & .957 \\
\hline Received aggression & $.660 \pm .345$ & 1.910 & .068 \\
\hline Treatment $\times$ isolation day & $-.964 \pm 2.211$ & -.436 & .669 \\
\hline Isolation day $\times$ received aggression & $-.706 \pm .414$ & -1.706 & .111 \\
\hline Treatment $\times$ received aggression & $-.460 \pm .442$ & -1.041 & .308 \\
\hline Treatment $\times$ isolation day $\times$ received aggression & $1.442 \pm .555$ & 2.595 & .023 \\
\hline \multicolumn{4}{|l|}{ e, Acceptance: } \\
\hline Intercept & $1.537 \pm .714$ & 2.153 & .031 \\
\hline Treatment & $-.910 \pm .576$ & -1.172 & .274 \\
\hline Isolation day & $.010 \pm .012$ & .890 & .373 \\
\hline Received aggression & $-.057 \pm .032$ & -1.777 & .076 \\
\hline Treatment $\times$ received aggression & $.079 \pm .043$ & 1.842 & .065 \\
\hline
\end{tabular}

Note: Sections $a-d$ refer to aggressive or submissive behavior of test fish toward the larger opponent; section $e$ refers to acceptance of test fish from all isolation groups between isolation day 0 and isolation day 60 . For factor names, see table 1. The covariate "received aggression" refers to aggression that the test fish received from the larger conspecific. The reference category for the estimate treatment is small groups; that for the isolation-day estimate in $b$ and $d$ is isolation day 0 ; in $a$, $c$, and $e$, isolation day was included as a covariate. $a, c, N=18$ family groups and 113 test fish; $b, d, N=18$ family groups and 34 observations; $e, N=18$ family groups and 110 observations. Boldface indicates $P<.05$; italics indicate $.05<P<.1$.

2003). Still, in most study systems it is poorly understood whether and through which mechanism developmental plasticity is adaptive. Among the adaptive explanations, the "environmental-matching" hypothesis has received substantial attention (e.g., Monaghan 2008; Uller 2008); it proposes that developing organisms adjust their phenotypes to cues, obtained either from parents (through parental effects) or from the early environment, that predict environmental conditions in the future. This hypothesis has become popular particularly in evolutionary medicine, where it has been proposed that mothers "program" their offspring's metabolism to cope better with poor future conditions ("predictive adaptive response"; Hales and Barker 2001; Gluckman et al. 2005). This hypothesis is currently strongly debated, however (Wells 2007; Hayward et al. 2013; Uller et al. 2013; Douhard et al. 2014). Preconditions for environmental matching include sufficiently high environmental variability and predictability (Burgess and Marshall 2014). A recent meta-analysis across organisms found only weak evidence for anticipatory plasticity through maternal effects (Uller et al. 2013). A main 
reason for this result may be that in many study systems environmental variability and predictability are too low (Burgess and Marshall 2014).

Our results may reflect environmental matching of phenotypes based on group size. Therefore, individuals, by means of their early social experience, might prepare for future conditions. These conditions require either a higher social competence (i.e., life in large social groups with a high diversity and frequency of social interactions; Limberger 1983; Cronin and Field 2007; Thavarajah et al. 2013) or a lower social competence (i.e., life in small social groups). Environmental matching with respect to group size is conceivable in our study species, because group sizes vary greatly in space and time, but from an individual perspective, group size is autocorrelated over time. Group size is relatively stable across years (Heg et al. 2005), and these fish have greatly delayed dispersal (Stiver et al. 2004). Alternatively, our results might be explained by the early social experience having a carryover effect on the adult's social performance (Stearns 1992; Monaghan 2008). This would mean that, regardless of the group sizes encountered later in life, individuals that grow up in larger, safer groups (Brouwer et al. 2005) would have an advantage over fish that grow up in small, unsafe groups. Currently, we are not able to differentiate between the two explanations, as this would have required orthogonal manipulations of early- and late-life environments (Uller et al. 2013; Burgess and Marshall 2014). Better social skills might also improve the immediate survival chances of juveniles during the first 2 months, when they received the social experience ("reactive plasticity"; Kasumovic 2013). This is unlikely, however, because improved social skills were observed only after, and not during, the experience phase of several ontogenetic experiments (Arnold and Taborsky 2010; Taborsky et al. 2012; S. Fischer, E. Oberhummer, C. Wikström, and B. Taborsky, unpublished manuscript).

Total brain size was unaffected by our treatments. This is noteworthy because increasing group size or the duration of social experience is expected to enhance environmental complexity, which in turn has been shown to increase brain size in several species (Gonda et al. 2013). Larger brains in fish reared in large groups may also have been expected, because, on an evolutionary timescale, it has been proposed that group size drives the evolution of brain size ("social-brain" hypothesis; Dunbar 1998). Instead, the MDS analysis revealed strong effects on relative brain part sizes. Brain architecture was interactively shaped by isolation day and rearing-group size. The interaction appears to be particularly caused by size differences of four large brain parts, which are interactively influenced by our treatments. Hypothalamus and cerebellum were larger in fish from small rearing groups isolated early and in fish from large groups isolated late, whereas the opposite pattern applied to the optic tectum and, as a tendency, also to the dor- sal medulla. The involved brain parts have a wide variety of functions and consist of different subregions (Butler and Hodos 2005; Striedter 2005), which makes it difficult to conclude the ultimate reasons for the observed differences. The optic tectum mainly receives and processes visual stimuli (Striedter 2005; Kotrschal et al. 2012a). An increase in optictectum size occurred in environments selecting for enhanced visual processing, including conditions of increased group sizes or population densities (Gonda et al. 2009; Ott and Rogers 2010). The hypothalamus has a number of different functions (Butler and Hodos 2005; Striedter 2005). Most importantly for the context of this study, it contains most of the brain nodes of the social behavior network, which has a key function for the control of social behavior and sociality (Goodson and Kabelik 2009) and, together with the mesolimbic reward system, forms the social decisionmaking network of vertebrates (O'Connell and Hofmann 2011). It is conceivable that the hypothalamus develops more strongly the longer fish are exposed to the more socially complex environment of large groups. The cerebellum and the dorsal medulla mainly control basic motor-control activities (Striedter 2005). Closer examinations revealed, however, that the cerebellum is also involved in a range of cognitive processes (Parkins 1997), and a comparative study in cichlids showed that cerebellum size correlates with habitat complexity (Pollen et al. 2007). Our developmental study supports this finding on an ecological timescale, as fish reared in large groups (i.e., a more complex social environment) and remaining in them until the end of the experience phase had a larger relative cerebellum size. There is an extensive debate among evolutionary biologists about whether selection acts on individual brain parts ("mosaic evolution"; de Winter and Oxnard 2001) or on overall brain size, with single brain parts being unable to evolve independently ("concerted evolution"; Finlay and Darlington 1995). Our data suggest that during development, relative brain parts change their size in response to environmental cues without affecting overall brain size. This indicates that increasing certain brain parts forces other parts to decrease in size concomitantly, lending support to mosaic brain development, at least on an ecological timescale.

The interactive effects of isolation day and group size on brain morphology and social behavior might have arisen if fish isolated early (day 0) from their natal groups were influenced differentially by the quality of (allo)parental care (Russell and Lummaa 2009), but these (allo)parental effects were attenuated or had entirely vanished during the following 2 months (see also Lindholm et al. 2006). Alternatively, these interactions might have been due to maternal effects on egg quality (Russell et al. 2007; Taborsky et al. 2007). Group-size manipulations in N. pulcher revealed that in large groups, breeders lay smaller and thus less energyrich eggs (Taborsky et al. 2007). If larvae hatching from 
small eggs are developmentally retarded, this may explain why juveniles from large groups separated at day 0 from their natal group had less developed social skills than earlyseparated juveniles originating from small groups and thus larger eggs. The longer juveniles were allowed to stay in the larger, socially more complex groups, the more they might have compensated for their initial deficit from large groups, while the opposite tendency occurred in juveniles originating from small groups. There was also a strong main effect of isolation day on brain morphology and social behavior. We would like to stress that this main effect must be interpreted with caution. The perceived environment during the first 2 months of life (especially the visual component) was quite different between fish isolated at day 0 and those isolated at day 60 . Fish isolated at day 0 shared a $10-\mathrm{L}$ tank with a few additional structures for hiding with 1-4 siblings. In contrast, test fish isolated on day 60 perceived a richly structured environment with adults, helpers, and more siblings in a large 200-L tank. Thus, the main effect of isolation day may to some part reflect the holding conditions of the fish. For instance, studies comparing various fish species reared in visually or socially enriched versus deprived environments (reviewed in Jonsson and Jonsson 2014) found that fish performed better in behavioral tasks if reared in reduced population densities (e.g., Brockmark et al. 2010) or more complex environments (e.g., Kihslinger and Nevitt 2006). Thus, we show that, in line with environmental complexity, individuals exposed to a more complex social environment during ontogeny obtain similar behavioral benefits. This has major implications for conservation strategies and especially for designing captive-rearing facilities for commercial as well as for scientific use.

To analyze whether there is a particularly sensitive time window within the 2-month experience phase of our rearing experiment, we isolated subgroups of young $N$. pulcher every 10 days, starting from experimental day 0 . Fish showed a linear increase of social behavior the longer they had stayed within their original family groups. There are two possible explanations why individuals isolated later from their family groups showed more social behaviors during the experience phase. (1) Juveniles staying longer with their family group had a longer time period to practice and develop their social skills, which is reflected by an increase of social behaviors. (2) Alternatively, experiences made during later stages of the experience phase might have had stronger effects on the development of behavior than those from earlier stages, resulting in more social behaviors when fish were isolated later from their family groups. Irrespective of the mechanism, the continuous increase of social behavior with time in the groups suggests that no classical sensitive period exists in $N$. pulcher during which significant influences on social behaviors take place. Rather, social behavior appears to remain plastic to some degree for extended periods of time, which may allow for certain behavioral adaptations both to early- and to later-life environments (Champagne and Meaney 2007; Bateson and Gluckman 2011; Fischer et al. 2014a). In general, sensitive periods should be expected to be sufficiently long to allow animals collecting all necessary information to reliably predict their future. For example, filial-imprinting windows in mammals and birds are typically very short, and young attach to the first individual they encounter, which almost always is their mother (Scott 1962). In contrast, the development of a complex repertoire of social behavior requires the opportunity for multiple social interactions and contexts, which makes short, welldefined sensitive periods less advantageous. However, it is problematic to draw conclusions about sensitive periods based on behavioral observations only, as complex behaviors may receive input from several neuronal circuits, each of which may have its own developmental regulation (Knudsen 2004)

Thus far, the research on group-size effects in social animals has largely focused on the immediate benefits and costs of being a member of a larger versus a smaller group, such as safety from predation (Treherne and Foster 1980; Fels et al. 1995), foraging efficiency (Creel and Creel 1995; Templeton and Giraldeau 1995), or reproductive success of group members (Balshine et al. 2001; Riehl 2013). Our results show that natal group size can also be an important priming factor in the development of social behavior and social competence. The plastic adjustment of social skills to early group size and the complexity of the social environment should be particularly beneficial to animals living in rather closed societies, such as cooperative breeders. In these species, (1) the variation in group size is typically high (e.g., Clutton-Brock et al. 1999; Cant 2006; Woxvold et al. 2006; Gusset and Macdonald 2010) and (2) for individuals the social environment is often autocorrelated over extended periods of their life because of stable group sizes and delayed dispersal (Clutton-Brock et al. 1999; Khan and Walters 2002; Heg et al. 2005).

There is a historical gap between disciplines studying ultimate functions and those studying underlying neural mechanisms of social behavior. It has been recently highlighted, however, that the study of social behavior would be particularly suited for an integrative research approach, as social behavior is ubiquitous in animals and crucial, and both the ecological conditions shaping social behavior and the physiological mechanisms regulating it are understood in great detail. Unfortunately, this knowledge has not accumulated in the same study systems (Hofmann et al. 2014). Here, we used an integrative approach to unravel potential joint influences of early social environment on social behavior, brain mechanisms, and ecological implications in an organism that serves as a model for the evolution of vertebrate sociality (Taborsky, forthcoming). Although we used 
a rather rough measure of brain architecture, we detected intriguing, repeated interactive effects of our treatments on both social performance and the relative sizes of major brain parts, suggesting that early social experience can link gross brain architecture and the expression of behavior. Previous studies linking social behavior or experience to brain struc. ture reported a remarkable reactive plasticity of the brain, even in adults. A study of rhesus macaques (Macaca mulatta) reported an increase in the amount of gray matter in different brain nodes in response to changes in social status (Noonan et al. 2014), and both brain size and the size of separate brain parts of adult guppies (Poecilia reticulata) changed in dependence of the sex of their social partner (Kotrschal et al. 2012a). Interestingly, the plastic adjustmen of brain architecture to early rearing conditions reported in this study was still present long after the experience phase Comparative studies have discussed the importance of brain size and of particular brain parts in the contexts of social cognition (Dunbar 1998) and the social and ecological com plexity of the environment (Kotrschal and Palzenberger 1992; Kotrschal et al. 1998; Pollen et al. 2007; Gonzalez-Voyer et al. 2009). However, while phylogenetic comparisons have the advantage that evolutionary trajectories can be traced, they are unable to fully control for species-specific factors confounded with the focal trait of interest (Harvey and Page ${ }^{1}$ 1998). Our approach demonstrates that, at least on ecological timescales, the connections between ecology, behavior, and brain mechanisms can be investigated efficiently by performing targeted developmental experiments in a singlc model organism.

\section{Acknowledgments}

We would like to thank D. Heg and M. Taborsky for their helpful input to this study and E. Zwygart for logistic support. We are grateful to J. L. Bronstein, J. Leips, and two anonymous reviewers for their valuable comments on an earlier version of the manuscript. We acknowledge finan. cial support from the Swiss National Science Foundation (31003A_133066 to B.T. and P2BEP3_155614 to S.F.), the Foundation Pierre Mercier, and the Austrian Science Func $\rightarrow$ (J 3304-B24 to A.K.).

\section{Literature Cited}

$\rightarrow$ Adkins-Regan, E., and A. Krakauer. 2000. Removal of adult males from the rearing environment increases preference for same-sex partners in the zebra finch. Animal Behaviour 60:47-53.

$\rightarrow$ Arnold, C., and B. Taborsky. 2010. Social experience in early ontogeny has lasting effects on social skills in cooperatively breedin cichlids. Animal Behaviour 79:621-630.

$\rightarrow$ Balshine, S., B. Leach, F. Neat, H. Reid, M. Taborsky, and N. Werner. 2001. Correlates of group size in a cooperatively breeding cichlid fish (Neolamprologus pulcher). Behavioral Ecology and Sociobiology 50:134-140.

Banerjee, S. B., A. S. Arterbery, D. J. Fergus, and E. Adkins-Regan. 2012. Deprivation of maternal care has long-lasting consequences for the hypothalamic-pituitary-adrenal axis of zebra finches. Proceedings of the Royal Society B: Biological Sciences 279:759-766.

Bastian, M. L., A. C. Sponberg, S. J. Suomi, and J. D. Higley. 2003. Long-term effects of infant rearing condition on the acquisition of dominance rank in juvenile and adult rhesus macaques ( $\mathrm{Ma}$ caca mulatta). Developmental Psychobiology 42:44-51.

Bates, D., M. Maechler, and B. Bolker. 2013. lme4: linear mixedeffects models using S4 classes. R package, version 0.999999-2. http://CRAN.R-project.org/package =lme4.

Bateson, P., and P. Gluckman. 2011. Plasticity, robustness, development and evolution. Cambridge University Press, Cambridge.

Bergmüller, R., and M. Taborsky. 2005. Experimental manipulation of helping in a cooperative breeder: helpers "pay to stay" by preemptive appeasement. Animal Behaviour 69:19-28.

Bertin, A., M. Hausberger, L. Henry, and M. A. Richard-Yris. 2007. Adult and peer influences on starling song development. Developmental Psychobiology 49:362-374.

Bester-Meredith, J. K., and C. A. Marler. 2007. Social experience during development and female offspring aggression in Peromyscus mice. Ethology 113:889-900.

Bolker, B. M., M. E. Brooks, C. J. Clark, S. W. Geange, J. R. Poulsen, M. H. Stevens, and J. S. White. 2009. Generalized linear mixed models: a practical guide for ecology and evolution. Trends in Ecology and Evolution 24:127-135.

Branchi, I. 2009. The mouse communal nest: investigating the epigenetic influences of the early social environment on brain and behavior development. Neuroscience and Biobehavioral Reviews 33: 551-559.

Branchi, I., I. D’Andrea, M. Fiore, V. Di Fausto, L. Aloe, and E. Alleva. 2006. Early social enrichment shapes social behavior and nerve growth factor and brain-derived neurotrophic factor levels in the adult mouse brain. Biological Psychiatry 60:690-696.

$\rightarrow$ Brockmark, S., B. Adriaenssens, and J. I. Johnsson. 2010. Less is more: density influences the development of behavioural life skills in trout. Proceedings of the Royal Society B: Biological Sciences 277: 3035-3043.

Brouwer, L., D. Heg, and M. Taborsky. 2005. Experimental evidence for helper effects in a cooperatively breeding cichlid. Behavioral Ecology 16:667-673.

Bruintjes, R., and M. Taborsky. 2011. Size-dependent task specialization in a cooperative cichlid in response to experimental variation of demand. Animal Behaviour 81:387-394.

Burgess, S. C., and D. J. Marshall. 2014. Adaptive parental effects: the importance of estimating environmental predictability and offspring fitness appropriately. Oikos 123:769-776.

$\rightarrow$ Burish, M. J., H. Y. Kueh, and S. S. H. Wang. 2004. Brain architecture and social complexity in modern and ancient birds. Brain, Behavior and Evolution 63:107-124.

Butler, A. B., and W. Hodos. 2005. Comparative vertebrate neuroanatomy: evolution and adaptation. Wiley, New York.

$\rightarrow$ Cant, M. A. 2006. Stable group size in cooperative breeders: the role of inheritance and reproductive skew. Behavioral Ecology 17:560-568.

Champagne, F. A., and M. J. Meaney. 2007. Trans-generational effects of social environment on variations in maternal care and behavioral response to novelty. Behavioral Neuroscience 121:13531363. 
$\rightarrow$ Chapman, B. B., A. J. W. Ward, and J. Krause. 2008. Schooling and learning: early social environment predicts social learning ability in the guppy, Poecilia reticulata. Animal Behaviour 76:923-929.

$\rightarrow$ Clark, D. A., P. P. Mitra, and S. S. H. Wang. 2001. Scalable architec $\rightarrow$ ture in mammalian brains. Nature 411:189-193.

$\rightarrow$ Clutton-Brock, T. H., D. Gaynor, G. M. McIlrath, A. D. C. Maccoll, R. Kansky, P. Chadwick, M. Manser, J. D. Skinner, and P. N. M $\rightarrow$ Brotherton. 1999. Predation, group size and mortality in a cooperative mongoose, Suricata suricatta. Journal of Animal Ecology 68:672-683.

$\rightarrow$ Clutton-Brock, T. H., S. J. Hodge, and T. P. Flower. 2008. Group sizı $\rightarrow$ and the suppression of subordinate reproduction in Kalahari meerkats. Animal Behaviour 76:689-700.

Crawley, M. J. 2007. The R book. Wiley, Chichester.

$\rightarrow$ Creel, S., and N. M. Creel. 1995. Communal hunting and pack size in African wild dogs, Lycaon pictus. Animal Behaviour 50:13251339.

$\rightarrow$ Cronin, A. L., and J. Field. 2007. Rank and colony defense against conspecifics in a facultatively eusocial hover wasp. Behavioral Ecolog 18:331-336.

$\rightarrow$ Cunningham, R. L., A. R. Lumia, and M. Y. McGinnis. 2013. Androgenic anabolic steroid exposure during adolescence: ramification: for brain development and behavior. Hormones and Behavior 64: 350-356.

$\rightarrow$ Dettling, A. C., J. Feldon, and C. R. Pryce. 2002. Early deprivation and behavioral and physiological responses to social separation novelty in the marmoset. Pharmacology Biochemistry and Behavior 73:259-269.

$\rightarrow$ de Winter, W., and C. E. Oxnard. 2001. Evolutionary radiations and convergences in the structural organization of mammalian brains $\rightarrow$ Nature 409:710-714.

$\rightarrow$ Dey, C. J., A. R. Reddon, C. M. O'Connor, and S. Balshine. 2013. Network structure is related to social conflict in a cooperatively breeding fish. Animal Behaviour 85:395-402.

$\rightarrow$ Dierkes, P., D. Heg, M. Taborsky, E. Skubic, and R. Achmann. 2005 Genetic relatedness in groups is sex-specific and declines with age of helpers in a cooperatively breeding cichlid. Ecology Letters 8: 968-975.

$\rightarrow$ Douhard, M., F. Plard, J. M. Gaillard, G. Capron, D. Delorme, F. Klein $\rightarrow$ P. Duncan, L. E. Loe, and C. Bonenfant. 2014. Fitness consequences of environmental conditions at different life stages in a long-lived vertebrate. Proceedings of the Royal Society B: Biological Sciences 281:20140276. doi:10.1098/rspb.2014.0276.

$\rightarrow$ Dunbar, R. I. M. 1998. The social brain hypothesis. Evolutionary Anthropology 6:178-190.

$\rightarrow$ Fels, D., A. A. Rhisiart, and F. Vollrath. 1995. The selfish crouton $\rightarrow$ Behaviour 132:49-55.

$\rightarrow$ Finlay, B. L., and R. B. Darlington. 1995. Linked regularities in the development and evolution of mammalian brains. Science 268: 1578-1584.

$\rightarrow$ Fischer, B., G. S. van Doorn, U. Dieckmann, and B. Taborsky. 2014a. The evolution of age-dependent plasticity. American Naturalist 183: $108-125$.

Fischer, S., M. Bessert-Nettelbeck, A. Kotrschal, and B. Taborsky. 2015. Data from: Rearing-group size determines social competence and brain structure in a cooperatively breeding cichlid. Amer $\rightarrow$ ican Naturalist, Dryad Digital Repository, http://dx.doi.org/10.5061 /dryad.s0b14.

$\rightarrow$ Fischer, S., M. Zöttl, F. Groenewoud, and B. Taborsky. $2014 b$. Group-size-dependent punishment of idle subordinates in a coop- erative breeder where helpers pay to stay. Proceedings of the Royal Society B: Biological Sciences 281:28120140184. doi:10.1098/rspb .2014.0184.

Gluckman, P. D., M. A. Hanson, and H. G. Spencer. 2005. Predictive adaptive responses and human evolution. Trends in Ecology and Evolution 20:527-533.

Gonda, A., G. Herczeg, and J. Merilä. 2009. Habitat-dependent and -independent plastic responses to social environment in the ninespined stickleback (Pungitius pungitius) brain. Proceedings of the Royal Society B: Biological Sciences 276:2085-2092.

. 2013. Evolutionary ecology of intraspecific brain size variation: a review. Ecology and Evolution 3:2751-2764.

$\rightarrow$ Gonzalez-Voyer, A., and N. Kolm. 2010. Sex, ecology and the brain: evolutionary correlates of brain structure volumes in Tanganyikan cichlids. PLoS ONE 5:e14355. doi:10.1371/journal.pone.0014355.

Gonzalez-Voyer, A., S. Winberg, and N. Kolm. 2009. Social fishes and single mothers: brain evolution in African cichlids. Proceedings of the Royal Society B: Biological Sciences 276:161-167.

Goodson, J. L., and D. Kabelik. 2009. Dynamic limbic networks and social diversity in vertebrates: from neural context to neuromodulatory patterning. Frontiers in Neuroendocrinology 30:429-441.

Gracceva, G., J. M. Koolhaas, and T. G. Groothuis. 2011. Does the early social environment affect structure and consistency of personality in wild-type male rats? Developmental Psychobiology 53: 614-623.

Gusset, M., and D. W. Macdonald. 2010. Group size effects in cooperatively breeding African wild dogs. Animal Behaviour 79:425-428.

$\rightarrow$ Hales, C. N., and D. J. P. Barker. 2001. The thrifty phenotype hypothesis. British Medical Bulletin 60:5-20.

Hamilton, I. M., D. Heg, and N. Bender. 2005. Size differences within a dominance hierarchy influence conflict and help in a cooperatively breeding cichlid. Behaviour 142:1591-1613.

Harvey, P. H., and M. D. Pagel. 1998. The comparative method in evolutionary biology. Oxford University Press, Oxford.

Hayward, A. D., I. J. Rickard, and V. Lummaa. 2013. Influence of early-life nutrition on mortality and reproductive success during a subsequent famine in a preindustrial population. Proceedings of the National Academy of Sciences of the USA 110:13886-13891.

Heg, D., Z. Bachar, L. Brouwer, and M. Taborsky. 2004. Predation risk is an ecological constraint for helper dispersal in a cooperatively breeding cichlid. Proceedings of the Royal Society B: Biological Sciences 271:2367-2374.

$\rightarrow$ Heg, D., L. Brouwer, Z. Bachar, and M. Taborsky. 2005. Large group size yields group stability in the cooperatively breeding cichlid Neolamprologus pulcher. Behaviour 142:1615-1641.

Hofmann, H. A., A. K. Beery, D. T. Blumstein, I. D. Couzin, R. L. Earley, L. D. Hayes, P. L. Hurd, et al. 2014. An evolutionary framework for studying mechanisms of social behavior. Trends in Ecology and Evolution 29:581-589.

$\rightarrow$ Hollis, F., C. Isgor, and M. Kabbaj. 2013. The consequences of adolescent chronic unpredictable stress exposure on brain and behavior. Neuroscience 249:232-241.

$\rightarrow$ Jones, B. M., A. S. Leonard, D. R. Papaj, and W. Gronenberg. 2013. Plasticity of the worker bumblebee brain in relation to age and rearing environment. Brain, Behavior and Evolution 82:250-261.

$\rightarrow$ Jonsson, B., and N. Jonsson. 2014. Early environment influences later performance in fishes. Journal of Fish Biology 85:151-188.

$\rightarrow$ Kasumovic, M. M. 2013. The multidimensional consequences of the juvenile environment: towards an integrative view of the adult phenotype. Animal Behaviour 85:1049-1059. 
$\rightarrow$ Khan, M., and J. Walters. 2002. Effects of helpers on breeder surviva $\rightarrow$ in the red-cockaded woodpecker (Picoides borealis). Behavioral Ecology and Sociobiology 51:336-344.

$\rightarrow$ Kihslinger, R. L., and G. A. Nevitt. 2006. Early rearing environmen $\rightarrow$ impacts cerebellar growth in juvenile salmon. Journal of Experimental Biology 209:504-509.

$\rightarrow$ Knudsen, E. I. 2004. Sensitive periods in the development of the brain and behavior. Journal of Cognitive Neuroscience 16:14121425.

Konings, A. 1998. Tanganyika cichlids in their natural habitat. Cichlid, Ettlingen.

$\rightarrow$ Kotrschal, A., B. Rogell, A. A. Maklakov, and N. Kolm. 2012a. Sex $\rightarrow$ specific plasticity in brain morphology depends on social environment of the guppy, Poecilia reticulata. Behavioral Ecology and Sociobiology 66:1485-1492.

$\rightarrow$ Kotrschal, A., L. F. Sundstrom, D. Brelin, R. H. Devlin, and N. Kolm. $2012 b$. Inside the heads of David and Goliath: environmental ef fects on brain morphology among wild and growth-enhanced coho salmon Oncorhynchus kisutch. Journal of Fish Biology 81:987-1002.

$\rightarrow$ Kotrschal, K., and M. Palzenberger. 1992. Neuroecology of cyprinids - comparative, quantitative histology reveals diverse brain pat terns. Environmental Biology of Fishes 33:135-152.

$\rightarrow$ Kotrschal, K., M. J. Van Staaden, and R. Huber. 1998. Fish brains evolution and environmental relationships. Reviews in Fish Biology and Fisheries 8:373-408.

$\rightarrow$ Kruskal, J. B. 1964. Nonmetric multidimensional scaling: a numerical method. Psychometrika 29:115-129.

$\rightarrow$ Kutsukake, N., and T. H. Clutton-Brock. 2006. Aggression and submission reflect reproductive conflict between females in cooperatively breeding meerkats Suricata suricatta. Behavioral Ecology and Sociobiology 59:541-548.

Kuznetsova, A., P. B. Brockhoff, and R. H. B. Christensen. 2013. lmerTest: tests for random and fixed effects for linear mixed effect models. R package Version 2.0-3. http://CRAN.R-project.org/package $=$ lmerTest.

$\rightarrow$ Levy, F., A. Melo, B. G. Galef, M. Madden, and A. Fleming. 2003. Complete maternal deprivation affects social, but not spatial, learning in adult rats. Developmental Psychobiology 43:177-191

$\rightarrow$ Limberger, D. 1983. Pairs and harems in a cichlid fish, Lamprologus brichardi. Zeitschrift für Tierpsychologie 62:115-144.

$\rightarrow$ Lindholm, A. K., J. Hunt, and R. Brooks. 2006. Where do all the ma $\rightarrow$ ternal effects go? variation in offspring body size through ontogeny in the live-bearing fish Poecilia parae. Biology Letters 2:586589.

$\rightarrow$ Machado, C. J., and J. Bachevalier. 2003. Non-human primate models of childhood psychopathology: the promise and the limitations. Journal of Child Psychology and Psychiatry 44:64-87.

$\rightarrow$ Macri, S., and H. Würbel. 2006. Developmental plasticity of HPA and fear responses in rats: a critical review of the maternal medi ation hypothesis. Hormones and Behavior 50:667-680.

$\rightarrow$ Malueg, A. L., J. R. Walters, and I. T. Moore. 2009. Do stress hormones suppress helper reproduction in the cooperatively breedin red-cockaded woodpecker (Picoides borealis)? Behavioral Ecology and Sociobiology 63:687-698.

$\rightarrow$ Monaghan, P. 2008. Early growth conditions, phenotypic develop ment and environmental change. Philosophical Transactions of the Royal Society B: Biological Sciences 363:1635-1645.

$\rightarrow$ Moretz, J. A., E. P. Martins, and B. D. Robison. 2007. The effects of early and adult social environment on zebrafish (Danio rerio) be $\rightarrow$ havior. Environmental Biology of Fishes 80:91-101.
Niemelä, P. T., and N. J. Dingemanse. 2014. Artificial environments and the study of "adaptive" personalities. Trends in Ecology and Evolution 29:245-247.

Noonan, M. P., J. Sallet, R. B. Mars, F. X. Neubert, J. X. O’Reilly, J. L. Andersson, A. S. Mitchell, A. H. Bell, K. L. Miller, and M. F. S. Rushworth. 2014. A neural circuit covarying with social hierarchy in macaques. PLoS Biology 12:e1001940. doi:10.1371/journal.pbio .1001940 .

O'Connell, L. A., and H. A. Hofmann. 2011. Genes, hormones, and circuits: an integrative approach to study the evolution of social behavior. Frontiers in Neuroendocrinology 32:320-335.

Oliveira, R. F. 2009. Social behavior in context: hormonal modulation of behavioral plasticity and social competence. Integrative and Comparative Biology 49:423-440.

$\rightarrow \quad$ 2012. Social plasticity in fish: integrating mechanisms and function. Journal of Fish Biology 81:2127-2150.

Ott, S. R., and S. M. Rogers. 2010. Gregarious desert locusts have substantially larger brains with altered proportions compared with the solitarious phase. Proceedings of the Royal Society B: Biological Sciences 277:3087-3096.

Parkins, E. J. 1997. Cerebellum and cerebrum in adaptive control and cognition: a review. Biological Cybernetics 77:79-87.

Pollen, A. A., A. P. Dobberfuhl, J. Scace, M. M. Igulu, S. C. P. Renn, C. A. Shumway, and H. A. Hofmann. 2007. Environmental complexity and social organization sculpt the brain in Lake Tanganyikan cichlid fish. Brain, Behavior and Evolution 70:21-39.

$\rightarrow$ Pryce, C. R., D. Ruedi-Bettschen, A. C. Dettling, A. Weston, H. Russig, B. Ferger, and J. Feldon. 2005. Long-term effects of early-life environmental manipulations in rodents and primates: potential animal models in depression research. Neuroscience and Biobehavioral Reviews 29:649-674.

R Development Core Team. 2013. R: a language and environment for statistical computing. http://cran.r-project.org/. R Project for Statistical Computing, Vienna.

Ricker, W. E. 1975. Growth rates and models. Pages 678-738 in W. S. Hoar, D. J. Randall, and J. R. Brett, eds. Fish physiology: bioenergetics and growth. Academic Press, London.

Riehl, C. 2013. Evolutionary routes to non-kin cooperative breeding in birds. Proceedings of the Royal Society B: Biological Sciences 280:20132245. doi:10.1098/rspb.2013.2245.

Rosenzweig, M. R., and E. L. Bennett. 1996. Psychobiology of plasticity: effects of training and experience on brain and behavior. Behavioural Brain Research 78:57-65.

$\rightarrow$ Russell, A. F., T. H. Clutton-Brock, P. N. M. Brotherton, L. L. Sharpe, G. M. McIlrath, F. D. Dalerum, E. Z. Cameron, and J. A. Barnard. 2002. Factors affecting pup growth and survival in cooperatively breeding meerkats Suricata suricatta. Journal of Animal Ecology 71:700-709.

Russell, A. F., N. E. Langmore, A. Cockburn, L. B. Astheimer, and R. M. Kilner. 2007. Reduced egg investment can conceal helper effects in cooperatively breeding birds. Science 317:941-944.

Russell, A. F., and V. Lummaa. 2009. Maternal effects in cooperative breeders: from hymenopterans to humans. Philosophical Transactions of the Royal Society B: Biological Sciences 364:1143-1167.

Scott, J. P. 1962. Critical periods in behavioral development. Science 138:949-958.

Stearns, S. C. 1992. The evolution of life histories. Oxford University Press, Oxford.

Stiver, K. A., P. Dierkes, M. Taborsky, and S. Balshine. 2004. Dispersal patterns and status change in a cooperatively breeding 
cichlid Neolamprologus pulcher: evidence from microsatellite anal $\rightarrow$ Templeton, J. J., and L. A. Giraldeau. 1995. Public information cues yses and behavioural observations. Journal of Fish Biology 65: 91-105. affect the scrounging decisions of starlings. Animal Behaviour 49: $1617-1626$

$\rightarrow$ Stiver, K. A., P. Dierkes, M. Taborsky, H. L. Gibbs, and S. Balshine $\rightarrow$ 2005. Relatedness and helping in fish: examining the theoretical predictions. Proceedings of the Royal Society B: Biological Sciences 272:1593-1599.

Striedter, G. F. 2005. Principles of brain evolution. Sinauer, Sunderland, MA.

$\rightarrow$ Sylvester, J. B., C. A. Rich, Y. H. E. Loh, M. J. van Staaden, G. J. Fraser, and J. T. Streelman. 2010. Brain diversity evolves via differ $\rightarrow$ ences in patterning. Proceedings of the National Academy of Sciences of the USA 107:9718-9723.

$\rightarrow$ Taborsky, B., C. Arnold, J. Junker, and A. Tschopp. 2012. The earl $\rightarrow$ social environment affects social competence in a cooperative breeder. Animal Behaviour 83:1067-1074.

$\rightarrow$ Taborsky, B., and R. F. Oliveira. 2012. Social competence: an evolutionary approach. Trends in Ecology and Evolution 27:679-688.

$\rightarrow$ Taborsky, B., E. Skubic, and R. Bruintjes. 2007. Mothers adjust egg size to helper number in a cooperatively breeding cichlid. Behavioral Ecology 18:652-657.

$\rightarrow$ Taborsky, B., L. Tschirren, C. Meunier, and N. Aubin-Horth. 2013. Stable reprogramming of brain transcription profiles by the early social environment in a cooperatively breeding fish. Proceedings of the Royal Society B: Biological Sciences 280:20122605. doi:10 $.1098 / \mathrm{rspb} .2012 .2605$.

Taborsky, M. 1982. Brutpflegehelfer beim Cichliden Lamprologubrichardi, Poll (1974): eine Kosten/Nutzen Analyse. PhD diss. University of Vienna.

$\rightarrow \longrightarrow$. 1984. Broodcare helpers in the cichlid fish Lamprologus brichardi: their costs and benefits. Animal Behaviour 32:1236-1252

$\rightarrow \longrightarrow$. 1985. Breeder-helper conflict in a cichlid fish with broodcare helpers: an experimental analysis. Behaviour 95:45-75.

havarajah, N. K., M. Fenkes, and T. H. Clutton-Brock. 2013. The determinants of dominance relationships among subordinate females in the cooperatively breeding meerkat. Behaviour 151:89-102.

$\rightarrow$ Treherne, J. E., and W. A. Foster. 1980. The effects of group size on predator avoidance in a marine insect. Animal Behaviour 28:1119-1122.

$\rightarrow$ Uller, T. 2008. Developmental plasticity and the evolution of parental effects. Trends in Ecology and Evolution 23:432-438.

Uller, T., S. Nakagawa, and S. English. 2013. Weak evidence for anticipatory parental effects in plants and animals. Journal of Evolutionary Biology 26:2161-2170.

van Praag, H., G. Kempermann, and F. H. Gage. 2000. Neural consequences of environmental enrichment. Nature Reviews Neuroscience 1:191-198.

van Staaden, M. J., R. Huber, L. S. Kaufman, and K. F. Liem. 1994. Brain evolution in cichlids of the African Great Lakes: brain and body size, general patterns, and evolutionary trends. Zoology Analysis of Complex Systems 98:165-178.

$\rightarrow$ Wells, J. C. K. 2007. Flaws in the theory of predictive adaptive responses. Trends in Endocrinology and Metabolism 18:331-337.

West-Eberhard, M. J. 2003. Developmental plasticity and evolution. Oxford University Press, New York.

Wheatherley, A. H., and H. S. Gill. 1987. The biology of fish growth. Academic Press, London.

$\rightarrow$ White, D. J., A. S. Gersick, G. Freed-Brown, and N. Snyder-Mackler. 2010. The ontogeny of social skills: experimental increases in social complexity enhance reproductive success in adult cowbirds. Animal Behaviour 79:385-390.

. Forthcoming. Ecology and evolution of cooperative breed $\rightarrow$ Z ing in cichlid fish. In W. Koenig and J. L. Dickinson, eds. Cooperative breeding: studies in ecology, evolution, and behaviour. Cambridge University Press, Cambridge.

$\rightarrow$ Taborsky, M., and D. Limberger. 1981. Helpers in fish. Behavioral Ecology and Sociobiology 8:143-145.

Woxvold, I. A., R. A. Mulder, and M. J. L. Magrath. 2006. Contributions to care vary with age, sex, breeding status and group size in the cooperatively breeding apostlebird. Animal Behaviour 72:63-73.

Zöttl, M., D. Heg, N. Chervet, and M. Taborsky. 2013. Kinship reduces alloparental care in cooperative cichlids where helpers payto-stay. Nature Communications 4:1341. doi:10.1038/ncomms2344.

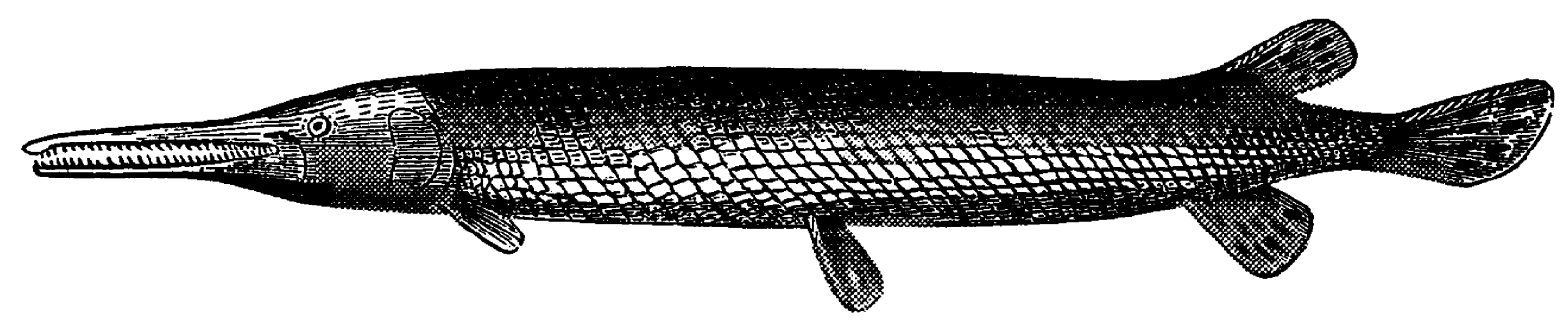

\begin{abstract}
"The Gar (Lepidosteus osseus [pictured]) . . . remained as motionless as an Esox for several minutes, and on the approach of a minnow would come as near the shore as possible, moving steadily backwards. If the fish came to about where the gar previously had been, it was seized in an instant, and the Lepidosteus would remain motionless until the approach of another Minnow would cause it to again draw back." From "Notes on Fresh-Water Fishes of New Jersey" by Charles C. Abbott (The American Naturalist, 1870, 4:99-117).
\end{abstract}

